\title{
Mila Blooms: \\ A Mobile Phone Application and Behavioral Intervention for Promoting Physical Activity and a Healthy Diet Among Adolescent Survivors of Childhood Cancer
}

\author{
Bernard F. Fuemmeler, PhD, MPH, ${ }^{1}$ Ed Holzwarth, BA, ${ }^{2}$ Yaou Sheng, MPH, ${ }^{1}$ Elizabeth K. Do, PhD, MPH, \\ Carrie A. Miller, PhD, MPH, ${ }^{1}$ Julie Blatt, MD, ${ }^{3}$ Philip M. Rosoff, MD, MA, ${ }^{4}$ and Truls Østbye, MD, $\mathrm{PhD}^{5}$
}

\begin{abstract}
Objectives: Smartphone applications ("apps") can be used to promote health behavior change and expand the reach of behavioral interventions. To date, only a few existing apps have been developed for health promotion among adolescent survivors of childhood cancer. To address this gap, we developed an app-based intervention, using game design characteristics, theory-based behavioral strategies, and assistance from a health coach to motivate health behavior change for adolescent survivors of childhood cancer. This article describes the development and initial feasibility evaluation of the intervention.

Methods: Using a theoretical framework and an extensive formative process, we developed an app-based game ("Mila Blooms") that promotes healthy eating and physical activity among adolescent survivors of childhood cancer. A single-arm 8-week intervention, using this app-based game, with assistance from a health coach, was conducted among a sample of pediatric cancer survivors $(n=15)$ to evaluate its initial feasibility for promoting health behavior change.

Results: Results from the feasibility evaluation were encouraging. The majority of enrolled participants were retained throughout the 8-week intervention (93.8\%). Participant satisfaction feedback indicated positive experiences, related to ease of use and enjoyment of the app. Although there was little evidence for behavior change attributable to the app in this first stage of development, there was a solid demonstration of the viability and appeal of the game features, and there were no adverse side effects.

Conclusions: Results provide insights into how gamification can be used to promote health behaviors through an app-based intervention. Mila Blooms holds promise for promoting health behavior change. Lessons learned from our experiences could be useful for the future development and implementation of app-based adolescent health interventions.
\end{abstract}

Keywords: Adoloscent cancer survivors, Health promotion, Gamification, mHealth

\section{Introduction}

$\mathbf{T}$ HERE ARE 429,000 CHILDHOOD cancer survivors in the United States. These survivors are at increased risk of becoming overweight or obese after treatment, ${ }^{1}$ which may exacerbate long-term health problems, ${ }^{2}$ including: decreased quality of life, ${ }^{3}$ cardiometabolic con- ditions, ${ }^{2}$ osteopenia, and secondary malignancies. ${ }^{4,5}$ To avoid excess weight gain, a diet rich in nutrient-dense, low-calorie foods, as well as optimal physical activity (PA) levels should be maintained throughout cancer treatment and into survivorship. Many survivors, however, are less likely than their healthy counterparts to adhere to such recommendations. ${ }^{6-13}$

\footnotetext{
${ }^{1}$ Department of Health Behavior and Policy, Virginia Commonwealth University, Richmond, Virginia.

${ }^{2}$ Pattern Health, Durham, North Carolina.

${ }^{3}$ Department of Pediatric Hematology Oncology Program, University of North Carolina, Chapel Hill, Chapel Hill, North Carolina.

${ }^{4}$ Department of Pediatrics and Medicine, Duke University, Durham, North Carolina.

${ }^{5}$ Department of Family Medicine and Community Health, Duke University, Durham, North Carolina.
} 
Only a few interventions exist to promote healthy lifestyle behaviors among this population. Since there are relatively few pediatric cancer survivors in any one location, participant recruitment and dissemination of existing interventions may be difficult. ${ }^{14}$ Additionally, health promotion programs should ideally be developmentally tailored, since there is a wide age range among survivors of pediatric cancers. Health promotion interventions should therefore be designed to be delivered at a distance and developmentally tailored to specific age groups. ${ }^{6,15}$

Rapid technological innovations in mobile technology, increasing availability of custom applications ("apps"), and decreasing cost for app development allow for the expansion of distance-based, health promotion approaches. ${ }^{16}$ The use of mobile devices to promote health behaviors show promise and acceptability, in both adults and children ${ }^{16,17}$ but many are not designed and tested for pediatric cancer survivors. ${ }^{18}$ Some existing apps provide tools for self-monitoring of diet, ${ }^{19}$ but few are specifically designed to motivate healthy behaviors in addition to diet (e.g., Cherry ${ }^{20}$ and Eating after Transplant [EAT!]). ${ }^{21}$

To address some of these challenges, we developed a distance-based health intervention relevant for adolescent survivors of pediatric cancer. Unique to our intervention was the use of game design characteristics and theory-based strategies to motivate health behavior change, including the use of a health coach in tandem with the app-based intervention. This article describes the development and feasibility evaluation of Mila Blooms, a smartphone app-based intervention, to pro- mote PA and a healthy diet among adolescent survivors of pediatric cancer.

\section{App Development Process}

\section{Theoretical framework}

Figure 1 illustrates the theoretical framework that guided the app development process. Central to this framework were social cognitive theory (SCT), self-determination theory (SDT), and narrative transportation theory. Key elements of SCT includes increasing self-efficacy for healthy lifestyle adoption through skill development, increasing behavioral capabilities, and improving social support. SDT emphasizes the importance of autonomy (choice), relatedness (feeling valued by others), and competence for developing intrinsic motivation for behavior change. As discussed by Przybylski et al. ${ }^{22}$ and Ryan et al., ${ }^{23}$ games foster intrinsic motivation by providing a context for people to make autonomous choices, experience pleasure, and feel competent for performing key behaviors to win the game. Within this context, game mechanics (e.g., points, badges, levels) facilitate engagement in playing a game and make the game fun rather than act as external rewards for a specific behavior (or behaviors). ${ }^{24}$ Narrative transportation theory emphasizes the importance of creating visual imagery in a narrative world and story line. This context allows for increasing acceptance of persuasive messages through multiple channels of cognitive processing. ${ }^{25,26}$ Thus, the app we sought to develop was intended to align with elements of these theories in that the aim was to

\section{DIGITALLY-MEDIATED INTERVENTION}

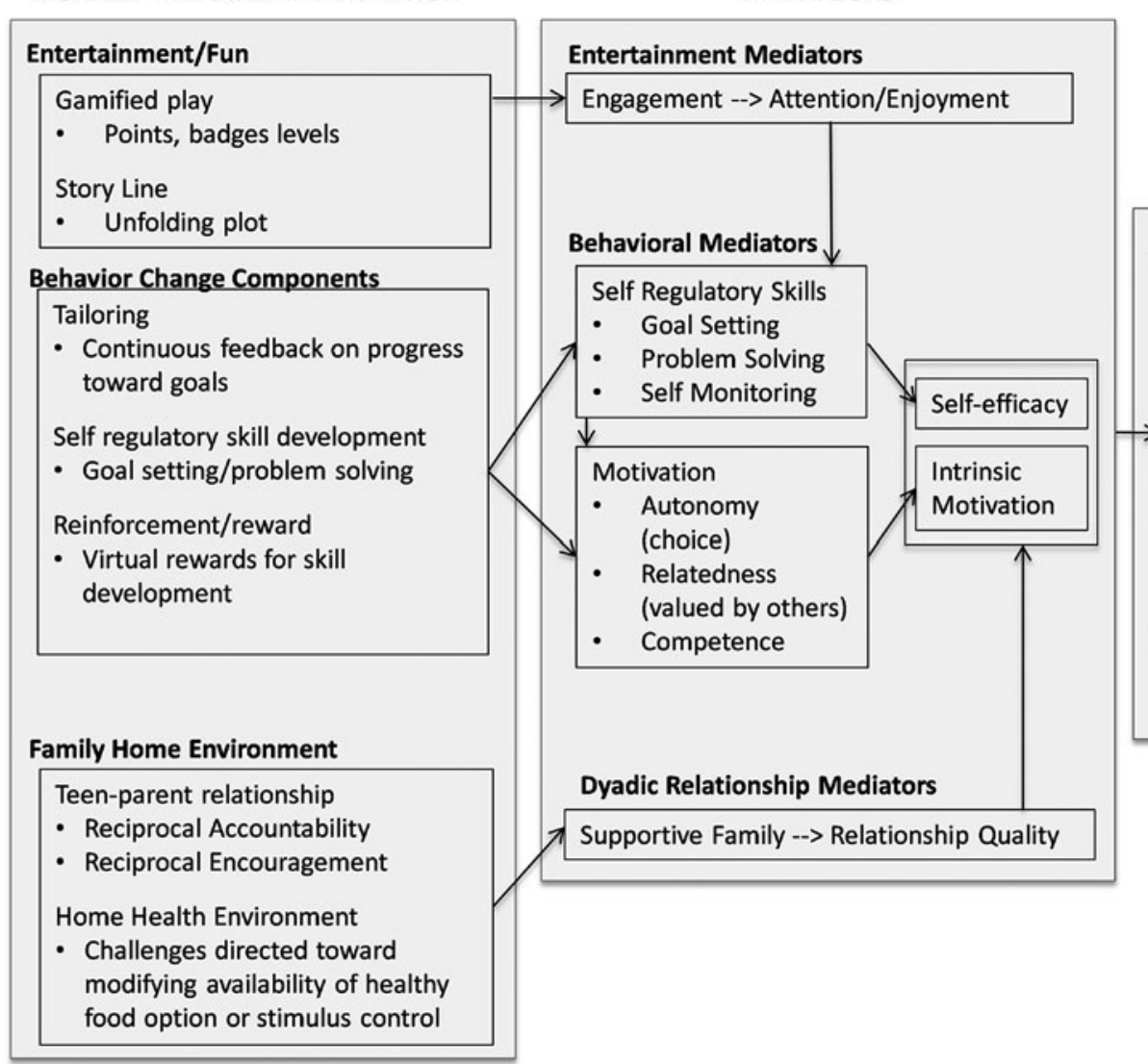

\section{TEEN-PARENT OUTCOMES}

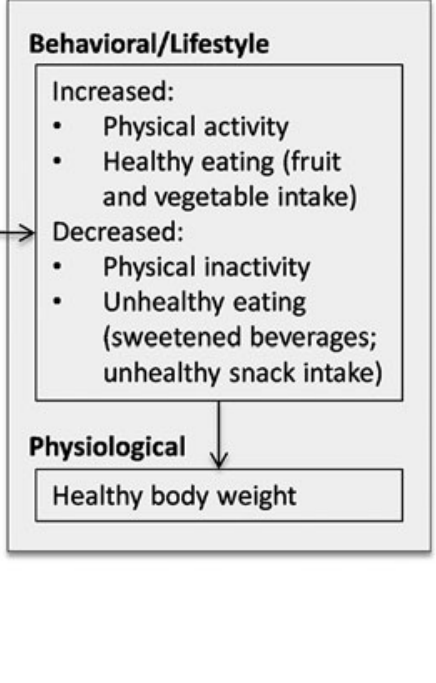

FIG. 1. Framework guiding development of app and intervention. 
provide (1) self-management tools to improve skill development relevant to healthy weight management, (2) a social component to improve social support by allowing players to communicate with one another as well as a coach, and (3) a game context, which included game mechanics and a narrative storyline that was intended to be fun and foster intrinsic motivation for engaging in healthy lifestyle behaviors.

\section{Design process}

There were extensive discussions between the study and software engineers to develop the visual imagery and a preliminary game concept. The overarching goal was to generate a game that would appeal to young adolescents and incorporated design features that increase loyalty to the game. Visual themes and imagery were chosen to convey a sense of fun and epic importance. ${ }^{27}$ A backstory was designed to create an epic journey to motivate play $^{23}$ and promote information processing. $^{28}$ To symbolize the "cancer journey," a mountain climbing expedition theme was employed. Based on our experience working with this population and the feedback we received from formative research, we thought this would resonate with cancer survivors because mountain climbing/ summiting is about overcoming goals and challenges similar to the cancer experience. Also, like the pediatric cancer experience, mountain expeditions require a team effort.

An initial game concept along with paper mock-ups of the app were developed and presented to parent/child dyads. A total of 16 child/parent dyad interviews were conducted. The children were 12 to 17 years old and had a history of acute lymphoblastic leukemia (ALL) or lymphoma but were at least 2 years off active treatment. A semistructured interview was employed where children were asked to provide feedback on the backstory and goal of the game. The backstory was provided in a graphic novel and the storyline unfolded weekly within the app, as participants completed different levels. The backstory involved a futuristic post-apocalyptic world, where a band of survivors attempt to restore Earth's balance. To do this, participants are challenged to “journey to Earth's highest peaks and uncover the healing properties of the Mila Bloom," rare flowers growing only at the tops of these peaks.

The feedback was mostly positive. Most indicated that they liked the storyline of the game and its mountain climbing theme. When interviewing the teenage participants about the game and who should play with them, they indicated that playing with other youth was acceptable, but would prefer that their parents not play the game with them. When asked how long the game should last, they agreed that an 8-week timeframe for the game was reasonable. In general, feedback from these interviews was used to modify the storyline, game mechanics (e.g., points, badges, and levels), how the game should be played, and the user interface (e.g., colors and design). Subsequently, an alpha version of the app and supporting backend administrative dashboard were developed (see below for more details). The app and associated backend administrative dashboard was first tested for functionality by having five teenagers, 15 to 17 years of age without a history of cancer, use the app as a group for a period of 12 days, and report any problems they had using the app. This process also allowed the research team to evaluate the functionality of the backend administrative dashboard. After 12 days, the study team met with the participants in a group format to discuss their impressions. Participants stated they did not fully understand how the backstory tied to features of the app and felt that the points and rewards in the game did not reflect their personal achievements. Based on this feedback, weekly challenges were integrated to better reveal the game's backstory and the points system was modified to reward both individual and group-based progress.

\section{The Mila Blooms App and Intervention}

The final app and intervention included three components: (1) an app and backend administrative dashboard; (2) brief phone meetings with a health coach; and (3) educational print materials for each child and parent. Figure 2 displays key screenshots of the app; specifically, the interfaces that allow a user to review their progress in the game, monitor their achievements, record and view individual progress toward behavioral goals, and interact with others through the social message networking feature (see below).

The game was set up such that team-based and individuallevel play would advance the game. At enrollment, participants were assigned one of several avatars with different abilities, as well as screen names to mask their identity. Participants were guided through eight expeditions: Base

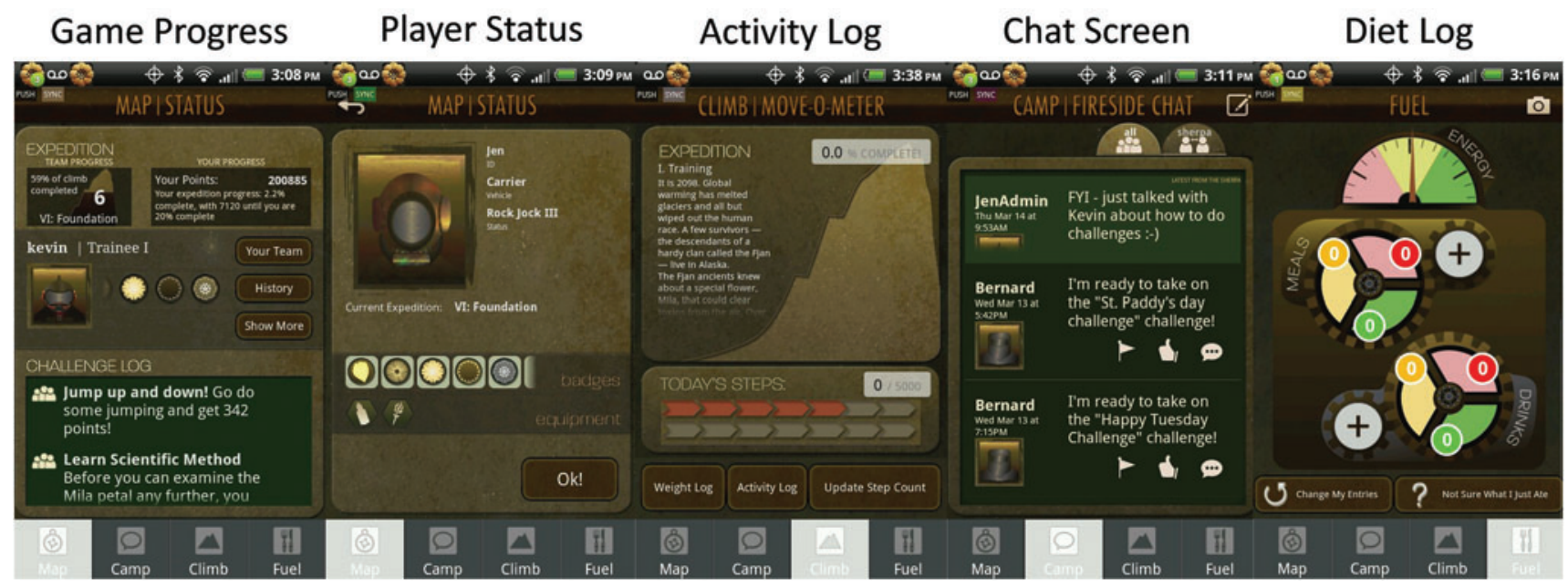

FIG. 2. Mila Blooms selected screenshots. Color images are available online. 
Camp, Discovery, Endurance, Stamina, Will Power, Foundation, Team Building, and Fortitude. For the whole group to move to the next expedition, every team member would need to complete the expedition. Participants were able to earn points and badges that signal individual progress.

To complete these expeditions, participants had to earn a sufficient number of points. Points were earned for each step recorded on the participant's pedometer, which was synched wirelessly with the phone, and for logging food intake corresponding to the stoplight diet. The stoplight diet categorizes foods according to fat and nutrient density, with red being foods being those with the most fat and lowest nutrients, which should be eaten infrequently, yellow foods being those with some fat and carbohydrates, which should be consumed in moderate amounts, and green foods which were rich in nutrients that should be consumed regularly, like fruits and vegetables $(\mathrm{FV}){ }^{29}$ Beverages were also entered using a similar color scheme with red beverages having the most sugar, yellow having moder- ate amounts of sugar, and green beverages having no sugar. ${ }^{30}$ Participants were given a listing of common foods and beverages in these categories. For every activity performed on the app there was automated feedback. For example, when the pedometer was synced, the user would receive feedback such as, "You're awesome and a tribute to the mission!" Logging red foods would result in feedback such as, "Ok thanks for logging. Limit Reds if possible-no more than 2/day."

Each expedition had 1-2 challenges designed to help improve behavioral skills relevant to weight management (e.g., measuring a serving size of food). A description of each expedition, associated mission themes, and challenges are provided in Table 1. Storyline progression and challenges were aligned with the game (example in Table 2). Completion of each challenge resulted in earning a currency ("lakhs") that could be exchanged for prizes obtained in a virtual store. The virtual store allowed participants to purchase special equipment and accessories, signaling success in the game. The health coach verified

Table 1. Themes and the Challenges Associated with Each Weekly Expedition

\begin{tabular}{|c|c|c|c|}
\hline Week & Expedition & Theme & Challenge \\
\hline 1 & Basecamp & Basics & $\begin{array}{l}\text { Orientation } \\
\text { Learn how to use the phone. } \\
\text { Get ready for the expedition! }\end{array}$ \\
\hline 2 & $\begin{array}{l}\text { Go to Denali to uncover the } \\
\text { mystery of the Mila } \\
\text { Blooms. }\end{array}$ & Discovery & $\begin{array}{l}\text { Portion sizing and nutrition } \\
\text { Find a place to buy a green food: take a picture or map it. } \\
\text { Take a picture of what you think a portion size is. } \\
\text { Measure out a serving size of your favorite snack and } \\
\text { send a picture. }\end{array}$ \\
\hline 3 & $\begin{array}{l}\text { Go to Moshi Tanzania to talk } \\
\text { with the snow leopards. }\end{array}$ & Endurance & $\begin{array}{l}\text { General physical activity } \\
\text { Map and take a quarter }(1 / 4) \text { mile walk near your home. } \\
\text { Post a positive thought about PA or something that } \\
\text { motivates you to be active. }\end{array}$ \\
\hline 4 & $\begin{array}{l}\text { Visit Australia to speak with } \\
\text { Glenn about the healing } \\
\text { powers of the Mila Blooms. }\end{array}$ & Stamina & $\begin{array}{l}\text { Increasing greens } \\
\text { Try a new fruit or vegetable every day this week. } \\
\text { Post your favorite green food on the message board. }\end{array}$ \\
\hline 5 & $\begin{array}{l}\text { Travel to Antarctica to } \\
\text { retrieve the ancient text } \\
\text { that was buried here. }\end{array}$ & Self-control & $\begin{array}{l}\text { Decreasing reds } \\
\text { Try replacing a red food with a healthier option and take a } \\
\text { picture of the swap. } \\
\text { Plan a healthy after-school snack and tell us about it. } \\
\text { Avoid fast food for } 3-5 \text { days. }\end{array}$ \\
\hline 6 & $\begin{array}{l}\text { Return to your village in } \\
\text { Alaska and begin } \\
\text { researching how to } \\
\text { propagate Mila Blooms for } \\
\text { world-wide dissemination. }\end{array}$ & Foundation & $\begin{array}{l}\text { Calcium bone health } \\
\text { Challenge yourself to get the recommended amount of } \\
\text { calcium. } \\
\text { Find and try a new/healthy calcium-rich food. Tell us } \\
\text { what you think about it. }\end{array}$ \\
\hline 7 & $\begin{array}{l}\text { Now that you've learned how } \\
\text { to grow Mila Blooms, build } \\
\text { a greenhouse so that you } \\
\text { can begin propagation. }\end{array}$ & Team building & $\begin{array}{l}\text { Social support/overcoming barriers } \\
\text { Recruit a friend or family member to try a new activity } \\
\text { this week. } \\
\text { Make a cue for yourself, such as laying out your workout } \\
\text { clothes the night before. } \\
\text { Post a barrier you have to, doing PA and give a solution to } \\
\text { someone else's barrier(s). }\end{array}$ \\
\hline 8 & $\begin{array}{l}\text { Trek around the world to } \\
\text { plant Mila Blooms. Your } \\
\text { trip will end once you've } \\
\text { planted on top of Mt. } \\
\text { Everest. }\end{array}$ & Fortitude & $\begin{array}{l}\text { Living it } \\
\text { Make and eat a healthier version of your favorite recipe. } \\
\text { Make a back-up plan for rainy days. } \\
\text { Tell us what you've learned! What are you going to } \\
\text { continue working on? }\end{array}$ \\
\hline 9 & & & $\begin{array}{l}\text { Wrap up } \\
\text { Wear your accelerometer. } \\
\text { Go to your follow-up visit. }\end{array}$ \\
\hline
\end{tabular}

PA, physical activity. 
Table 2. Example Expedition Narrative, Associated Challenge, and Response for Challenge Completion

\begin{tabular}{|c|c|c|}
\hline Expedition & Challenge & Response \\
\hline $\begin{array}{l}\text { It was just another ordinary day in the Metrocom pod, when } \\
\text { you stumble across a mysterious petal, which appears to } \\
\text { have floated unscathed through the advanced filter system. } \\
\text { Its glowing hue is unlike anything you have seen before. You } \\
\text { decide to take it to Janna, the camp's head scientist, to learn } \\
\text { more. Janna's eyes light up the instant she sees the petal. } \\
\text { Curious, you ask her why she seems so excited and she tells } \\
\text { you about a letter from her grandmother that mentions one } \\
\text { very special and vary rare flower called MILA Celestial } \\
\text { Bloom. It's a curious flower, which only thrives and } \\
\text { reproduces in large growing colonies. Janna's hunch is that } \\
\text { you have discovered proof of the legendary celestial blooms } \\
\text { that must have been trapped in the Metrocom's filter system } \\
\text { for years, but she can't be sure. To be sure, you will need to } \\
\text { study this further and run some experiments with Janna in } \\
\text { her lab. }\end{array}$ & $\begin{array}{l}\text { Before you can examine the } \\
\text { Mila petal any further, you } \\
\text { must first learn about the } \\
\text { scientific method. All } \\
\text { scientists must be able to } \\
\text { make careful } \\
\text { measurements. To practice } \\
\text { your measurement skills, } \\
\text { measure out } 1 \text { serving size } \\
\text { of your favorite snack } \\
\text { (healthy or unhealthy). } \\
\text { Snap a picture of your } \\
\text { measurement and send it to } \\
\text { the group and the Sherpa } \\
\text { along with a text message } \\
\text { about its nutritional content } \\
\text { (e.g., calories). }\end{array}$ & $\begin{array}{l}\text { Excellent work! Upon } \\
\text { closer observation, } \\
\text { you discover that } \\
\text { Mila bloom's vibrant } \\
\text { yellow hue is from } \\
\text { tiny crystals that coat } \\
\text { its unique petals. } \\
\text { Janna pays you in } \\
\text { lakhs for your hard } \\
\text { work. }\end{array}$ \\
\hline
\end{tabular}

the challenge completion by reviewing the participants post on the social network messaging feature of the app. For completing each expedition, participants were rewarded a badge, bronze, silver, and gold depending on how many points they earned. To advance to the next expedition everyone on the team had to earn a predetermined, minimum number of points.

The social network messaging feature of the app allowed for bidirectional text messaging between the participants and between the participants and the health coach. Using this feature, participants were able to post pictures and encourage other participants by pressing a "thumbs-up" icon. A "flag", icon allowed participants to automatically remove messages that they deemed inappropriate.

As shown in Figure 3, a backend dashboard was also developed. This feature, accessible only to the research team and health coach. The dashboard allowed the team to: (1) monitor participants' progress in real-time; (2) send messages to individual users or broadcast to all users; (3) monitor flagged messages or content posted on social network; (4) update or adjust the game mechanics (e.g., calibrate algorithms for points, or add expeditions or badges); (5) alter the content of the automated feedback messages; and (6) program challenges for release at prespecified times.

Finally, print-based materials were provided to participants and their parents. Adolescent participants received a "field guide" - a graphic novel describing the storyline of the game with information on what to expect each week and how to earn points. The materials for the parents included information and strategies for making their home environment

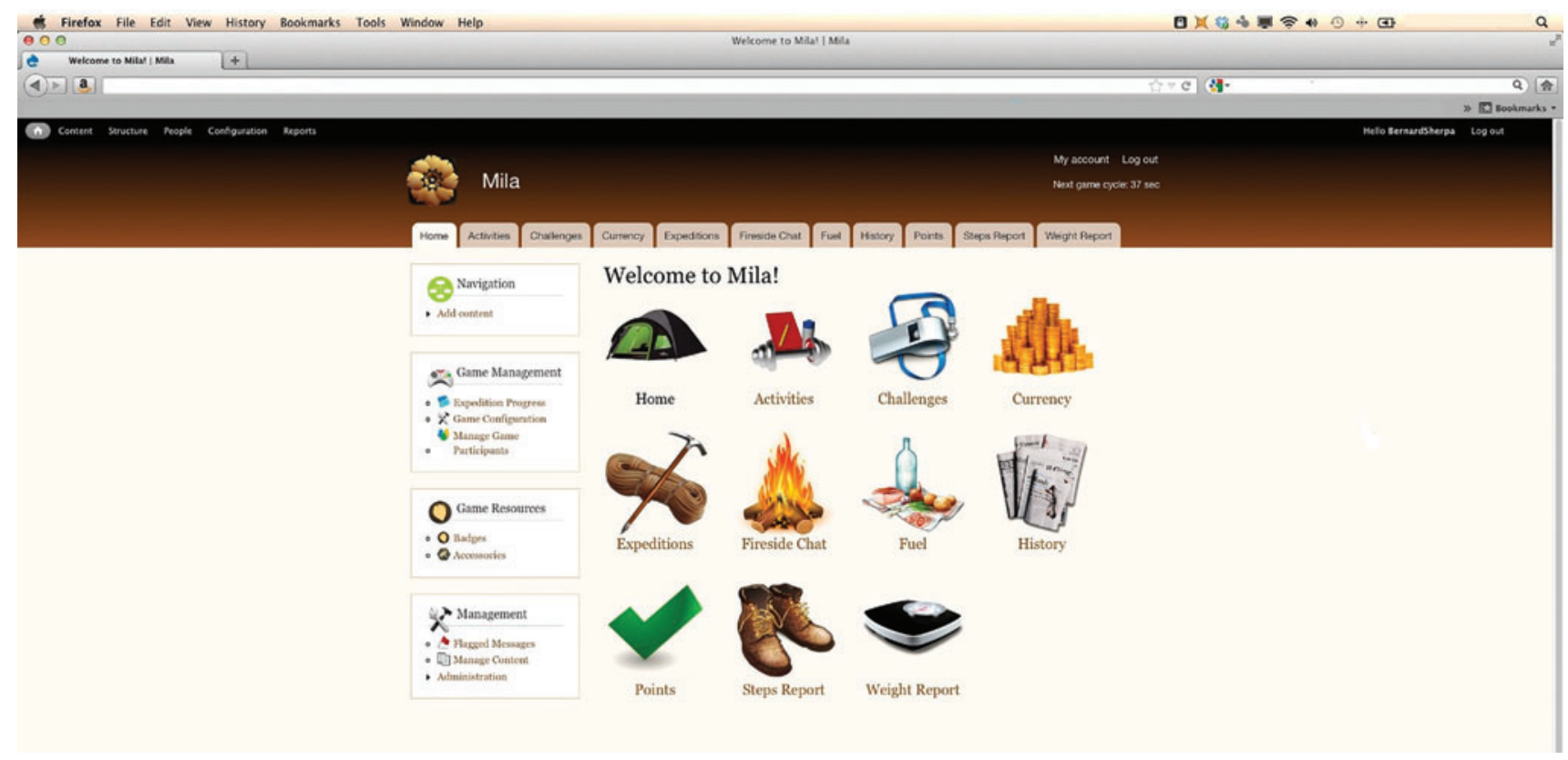

FIG. 3. Mila Blooms dashboard. Color images are available online. 
more supportive of healthy eating and PA while their child was playing the game.

\section{Feasibility Evaluation}

\section{Participants and procedures}

We used a quasiexperimental single-group pretest/posttest design to assess the feasibility of the Mila Blooms app and intervention. Parent/child dyads $(n=16)$ were recruited from two pediatric oncology clinics, one at Duke University and the other at University of North Carolina, Chapel Hill. Working with our physician partners, we received a list of 40 potentially eligible participants. Eligibility included being 12-17 years of age, having a history of ALL or lymphoma, and being off treatment for at least 2 years. Parents of eligible teenagers were mailed letters describing the study and inviting their participation. All study procedures were approved by the University's Institutional Review Board (IRB). Informed parental consent and adolescent assent were obtained for all participants. The app, data transfer, and administrative dashboard met the data security requirements of the University Health System and IRB.

The feasibility evaluation involved three in-person office visits. At the first visit, participants completed surveys and were instructed to wear accelerometers for 1 week. Study staff also measured participant height and weight. One week later, participants were introduced to the app and intervention. Each adolescent was provided a smartphone (an HTC Rhyme, Android 2.3.4 Gingerbread, which was returned at the end of the study), pedometer, field guide, and were assigned an avatar. During the 8-week intervention a research assistant with a bachelor's degree (health coach, or "Sherpa") trained in using brief motivational interviewing techniques and the studydesigned treatment manual, conducted a 15-minute phone interview with each participant. Sherpas worked with participants to help them advance through the game by setting reasonable diet and PA goals. Every 2 weeks, parents were sent (through postal service) a newsletter containing information about the health focus of the weeks' expeditions, as well as educational resources to create a healthy home environment (materials could be sent through e-mail, if requested). After the intervention, participants wore the accelerometer for an additional week. Height, weight, and survey data were collected and adolescents and parents participated in a focus group to discuss their experiences. For their time and participation, adolescents were compensated $\$ 50$ for completing the baseline survey and $\$ 50$ for the follow-up survey. No additional compensation was provided for using the smartphone or app.

\section{Measures}

Anthropometrics. Adolescent height and weight were measured by study staff and values along with age and sex were used to calculate body mass index, z-score, and percentile. ${ }^{31}$

Dietary intake. A paper version of the Block Kids 2004 self-report food frequency questionnaire (FFQ) was used to measure dietary intake. ${ }^{32-34}$ Questionnaires were scored by NutritionQuest, which provides a range of scores on macronutrients. ${ }^{35}$ Along with overall energy intake (kcal), key nutrient groups that were targeted in the intervention were evaluated (i.e., total fat, dietary fiber, dietary fiber from FV, average daily servings of FV, percent of kcal from sweets, and average daily grams from sugary beverages).

Physical activity. Adolescent PA was measured with triaxial accelerometers (ActiGraph ${ }^{\mathrm{TM}} \mathrm{GT} 3 \mathrm{X}+$ activity monitor). Participants were instructed to wear the device around their waist for 24 hours a day for six consecutive days. Accelerometer data were downloaded and analyzed using the ActiLife V6.11.9 software. Participants had to have at least 5 days with 5 hours of minimum wear-time per day to be included in the analyses. The Freedson Child (2005) algorithm was used to categorize activity levels based on child-specific cut points for counts per minute. ${ }^{36}$ For our purposes, we present average daily minutes of activity in the moderate-tovigorous range (moderate-to-vigorous physical activity [MVPA]) and percent of the total time in sedentary activity.

Diet and PA self-efficacy. The PACE Adolescent Psychosocial Measures for $\mathrm{PA}^{37}$ and FV confidence ${ }^{38}$ were used to assess adolescent self-efficacy related to PA and FV consumption.

User satisfaction and narrative engagement. During a posttest survey, participants were also asked to report on their perceived ease of use and enjoyment of the app, using 5-point Likert scales. Specifically, participants were asked: how easy it was to enter in dietary and PA information, how much they enjoyed specific features of the game, and how much they liked the graphic novel presenting the storyline of the game. At this same time period, participants were also asked about narrative engagement using the Transport Narrative Questionnaire. ${ }^{39}$ This 12 -item questionnaire assessed the phenomenological experience of being absorbed in a story. One item that asked if the participant had a "vivid mental image of the [character name]" was dropped since there was not a particular "character" in the narrative.

\section{Plan of analysis}

We compare the differences in mean changes in the set of measures from the period before receiving the Mila Blooms app and intervention materials (pretest) to the period immediately following the intervention (posttest). We further summarized the mean and standard deviations (SDs) for each of the measures by app usage defined as using app for $\geq 4$ weeks $(n=8)$ versus not $(n=7)$. To arrive at app usage, we assessed whether participants were earning points in the app for syncing their pedometer or logging their food. We used a repeated measure analysis of covariance (ANCOVA) adjusted for age, race, and sex to compare the differences in mean changes from pretest to posttest overall and by app usage (i.e., time*user group interaction). Mean and SDs and proportions of responses were also calculated to assess narrative engagement and user satisfaction, respectively.

\section{Results}

Sixteen adolescents were enrolled over a 6- to 8-month period. One participant completed the baseline visit, but during the first week of the study indicated that he was no longer interested in participating and thus was withdrawn from the study. Among the remaining 15, the mean age was 14.8 years $(\mathrm{SD}=1.97)$. Sixty percent were male $(n=9)$ and 
Table 3. Changes in Adolescent Diet, Physical Activity, and Weight $(n=15)$, App Users Versus Nonusers

\begin{tabular}{|c|c|c|c|c|}
\hline & $\begin{array}{c}\text { Baseline } \mathrm{M} \\
(S D)\end{array}$ & $\begin{array}{c}\text { Follow-up } \mathrm{M} \\
(S D)\end{array}$ & $\mathrm{P}^{\mathrm{a}}$ & $\mathrm{P}^{\mathrm{b}}$ \\
\hline \multicolumn{5}{|c|}{ Block diet measure } \\
\hline $\begin{array}{l}\text { Energy intake (k } \\
\text { Total } \\
\text { Not used app } \\
\text { Used app }\end{array}$ & $\begin{array}{l}1509.7(1445.3) \\
1787.0(2053.0) \\
1267.1(648.9)\end{array}$ & $\begin{array}{l}1474.6(1329.4) \\
1706.6(1811.4) \\
1271.7(788.1)\end{array}$ & $\begin{array}{l}0.693 \\
0.327 \\
0.783\end{array}$ & 0.991 \\
\hline $\begin{array}{l}\text { Total fat }(\mathrm{g}) \\
\text { Total } \\
\text { Not used app } \\
\text { Used app }\end{array}$ & $\begin{array}{l}59.7(62.3) \\
75.6(87.1) \\
45.8(28.2)\end{array}$ & $\begin{array}{l}56.4(50.9) \\
66.9(67.3) \\
47.3(33.2)\end{array}$ & $\begin{array}{l}0.625 \\
0.248 \\
0.661\end{array}$ & 0.686 \\
\hline $\begin{array}{l}\text { Dietary fiber }(\mathrm{g}) \\
\text { Total } \\
\text { Not used app } \\
\text { Used app }\end{array}$ & $\begin{array}{l}12.7(13.9) \\
15.0(20.4) \\
10.7(4.5)\end{array}$ & $\begin{array}{l}12.5(12.4) \\
12.5(16.9) \\
12.4(7.8)\end{array}$ & $\begin{array}{l}0.244 \\
0.181 \\
0.746\end{array}$ & 0.332 \\
\hline $\begin{array}{l}\text { Dietary fiber fror } \\
\text { Total } \\
\text { Not used app } \\
\text { Used app }\end{array}$ & $\begin{array}{l}5.0(3.9) \\
4.8(5.2) \\
5.2(2.7)\end{array}$ & $\begin{array}{l}5.2(4.6) \\
4.2(6.1) \\
6.2(2.9)\end{array}$ & $\begin{array}{l}0.103 \\
0.278 \\
0.421\end{array}$ & 0.177 \\
\hline $\begin{array}{l}\text { Servings of FV } \\
\text { Total } \\
\text { Not used app } \\
\text { Used app }\end{array}$ & $\begin{array}{l}3.0(2.4) \\
3.2(3.5) \\
2.9(1.0)\end{array}$ & $\begin{array}{l}2.9(2.5) \\
2.9(3.3) \\
2.9(1.9)\end{array}$ & $\begin{array}{l}0.176 \\
0.164 \\
0.819\end{array}$ & 0.711 \\
\hline $\begin{array}{l}\text { Percent of kcal } \mathrm{f} \\
\text { Total } \\
\text { Not used app } \\
\text { Used app }\end{array}$ & $\begin{array}{l}8.6(4.8) \\
8.8(6.3) \\
8.4(3.6)\end{array}$ & $\begin{array}{r}10.7(7.8) \\
7.5(4.8) \\
13.5(9.0)\end{array}$ & $\begin{array}{l}0.451 \\
0.347 \\
0.115\end{array}$ & 0.049 \\
\hline $\begin{array}{l}\text { Average daily g } \\
\text { Total } \\
\text { Not used app } \\
\text { Used app }\end{array}$ & $\begin{array}{l}\text { erages } \\
267.3(287.9) \\
336.8(367.7) \\
206.5(202.1)\end{array}$ & $\begin{array}{l}256.4(308.3) \\
370.4(410.9) \\
156.6(145.0)\end{array}$ & $\begin{array}{l}0.164 \\
\mathbf{0 . 0 3 7} \\
0.080\end{array}$ & 0.038 \\
\hline $\begin{array}{l}\text { Accelerometer } \\
\text { Average minutes } \\
\text { Total } \\
\text { Not used app } \\
\text { Used app }\end{array}$ & $\begin{array}{l}\text { r day } \\
152.3(55.2) \\
143.1(42.8) \\
160.3(66.1)\end{array}$ & $\begin{array}{l}128.8(59.5) \\
114.5(80.0) \\
139.5(41.1)\end{array}$ & $\begin{array}{l}\mathbf{0 . 0 0 5} \\
\mathbf{0 . 0 0 5} \\
0.228\end{array}$ & 0.124 \\
\hline $\begin{array}{l}\text { Percent of time } \mathrm{i} \\
\text { Total } \\
\text { Not used app } \\
\text { Used app }\end{array}$ & $\begin{array}{l}\text { ctivity } \\
79.9(5.6) \\
80.5(5.1) \\
79.3(6.2)\end{array}$ & $\begin{array}{l}82.9(7.2) \\
85.5(9.5) \\
80.8(4.6)\end{array}$ & $\begin{array}{l}\mathbf{0 . 0 2 1} \\
\mathbf{0 . 0 0 3} \\
0.459\end{array}$ & 0.038 \\
\hline $\begin{array}{l}\text { BMI } \\
\text { Total } \\
\text { Not used app } \\
\text { Used app }\end{array}$ & $\begin{array}{l}22.6(3.4) \\
22.7(2.7) \\
22.6(4.1)\end{array}$ & $\begin{array}{l}23.0(3.4) \\
23.1(2.6) \\
22.8(4.1)\end{array}$ & $\begin{array}{l}0.226 \\
0.242 \\
0.413\end{array}$ & 0.615 \\
\hline $\begin{array}{l}\text { BMI percentile } \\
\text { Total } \\
\text { Not used app } \\
\text { Used app }\end{array}$ & $\begin{array}{l}69.9(23.6) \\
70.7(27.7) \\
69.1(21.3)\end{array}$ & $\begin{array}{l}71.8(20.1) \\
74.2(17.8) \\
69.8(22.9)\end{array}$ & $\begin{array}{l}0.431 \\
0.252 \\
0.883\end{array}$ & 0.767 \\
\hline $\begin{array}{l}\text { PACE measures } \\
\text { FV self-efficacy }\end{array}$ & & & & \\
\hline $\begin{array}{l}\text { Total } \\
\text { Not used app } \\
\text { Used app }\end{array}$ & $\begin{array}{l}4.1(0.8) \\
4.0(0.8) \\
4.2(0.8)\end{array}$ & $\begin{array}{l}4.2(0.6) \\
4.0(0.6) \\
4.3(0.6)\end{array}$ & $\begin{array}{l}\mathbf{0 . 0 4 6} \\
0.240 \\
0.352\end{array}$ & 0.804 \\
\hline $\begin{array}{l}\text { PA self-efficacy } \\
\text { Total } \\
\text { Not used app } \\
\text { Used app }\end{array}$ & $\begin{array}{l}3.9(0.8) \\
4.3(0.6) \\
3.5(0.7)\end{array}$ & $\begin{array}{l}4.0(0.8) \\
4.1(0.8) \\
3.9(1.0)\end{array}$ & $\begin{array}{l}0.425 \\
0.318 \\
0.526\end{array}$ & 0.515 \\
\hline
\end{tabular}

App usage defined as: used app (use of app for 4 weeks or more) and not used app (app used for less than 4 weeks). All significance testing done by repeated measures ANCOVA, controlling for sex, race, and age. Bold are $P$-values $<0.05$.

${ }^{\mathrm{a}} P$-values for the main effect of time.

${ }^{\mathrm{b}} P$-values for the interaction of group and time.

ANCOVA, analysis of covariance; BMI, body mass index; FV, fruits and vegetables; g, grams; kcal, kilocalories; $M$, mean; MVPA, moderate-to-vigorous physical activity; SD, standard deviation. 
$87 \%(n=13)$ were White. Within our sample, $67 \%$ of mothers reported a college degree or higher, $27 \%$ reported an annual household income of less than $\$ 30,000,33 \%$ reported a household income between $\$ 30,000$ and $\$ 75,000$, and $40 \%$ reported a household income above $\$ 75,000$.

Mean and SDs for measures at pretest and posttest are shown in Table 3. Significant pretest to posttest changes were observed for MVPA (decrease from pretest to posttest), percent time in sedentary activity (increase from pretest to posttest), and FV self-efficacy (increase from pretest to posttest $)(P \mathrm{~s}<0.05)$. When examining the data by app usage status and time in a group-by-time interaction, statistically significant results were observed for percent of calories from sweets, average daily grams from sugary beverages, and percent of time spent in sedentary activity $(P \mathrm{~s}<0.05)$. There was a trend for the group-by-time interaction for the amount of time spend in MVPA, as the main effects showed that those who did not use the app decreased $(P=0.005)$, whereas those who used the app neither increased nor decreased $(P=0.23)$. The group-by-time interaction for calories consumed from sweets showed no significant main effect for the groups, but a significant increase among those who used the app $(P=0.049)$. The group-by-time interaction for average daily grams from sugary beverages showed that those who did not use the app increased from pretest to posttest $(P=0.04)$, whereas those who used the app showed a trend toward a decrease over time $(P=0.08)$. The group-by-time interaction for percent time in sedentary activity showed that those who did not use the app had a significantly greater increase in percent sedentary time $(P=0.003)$, whereas those who used the app neither increased nor decreased $(P=0.45)$. There were no statistical differences detected in changes in body mass, dietary self-efficacy, or servings of FV.

Participants were asked to log foods as they consumed them (preferably 2-3 times a day) and to once daily sync their pedometer (and/or record their PA not captured using a pedometer). They were asked to complete two challenges a week and were able to post a message or comment at any time. Thus, across 15 participants for 60 days, 3 food entries a day would equal 2700 points; 1 entry of activity a day would equal 900 points; completing 2 challenges a week would equal 240 points. Among our 15 participants, we observed 2116 entries of dietary data, 573 entries of PA data either through syncing the pedometer $(n=388)$ or manual entry $(n=185)$, and 35 completed challenges. There were 143 incidences of message posting $(n=127)$ and postings of comments $(n=16)$.

Posttest survey data on user satisfaction are presented in Figure 4. Most participants indicated that the app was somewhat easy or very easy to use. High levels of enjoyment, especially earning points in the game, were reported. With regard to narrative engagement, those who used the app reported slightly higher mean scores, but these were not statistically significantly higher $(M=3.2, \mathrm{SD}=1.1$ vs. $M=2.7$, $\mathrm{SD}=1.0, P=0.35)$. A ranking of mean scores for the items of this scale (Table 4) suggest some aspects of the narrative were engaging, but it was not viewed as emotionally engaging or having a substantial impact on one's life.

\section{Discussion}

This article describes the development and initial feasibility evaluation of Mila Blooms, a smartphone app-based game focused on the promotion of a healthy diet and PA among pediatric cancer survivors. Participant satisfaction feedback indicated positive experiences related to ease of use and enjoyment of the app. Positive feedback is attributed to purposeful inclusion and involvement of the target population at each step. Formative interviews and pilot testing with pediatric cancer survivors and otherwise healthy teenagers was critical to the design of the smartphone app and game, including program branding, interface, and functionalities. Also, highlighting our unique approach, the app design incorporated evidence-based theoretical frameworks of behavior change and game design.

Modest change in some of the key targeted behaviors were observed. However, our data tell a nuanced story. For instance, one of the goals was to increase MVPA and reduce time spent in sedentary activity, but when examining the data, we found that MVPA decreased and sedentary activity increased. When we further examined the data by app user group status, we found that those who were not using the app

How easy or difficult was it to...

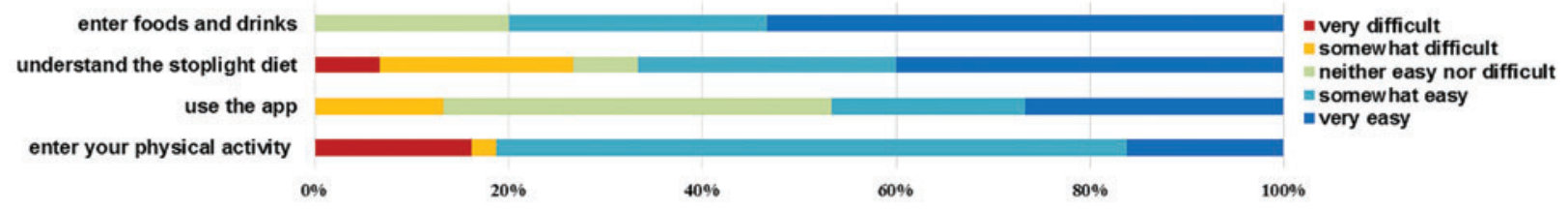

How much did you enjoy...

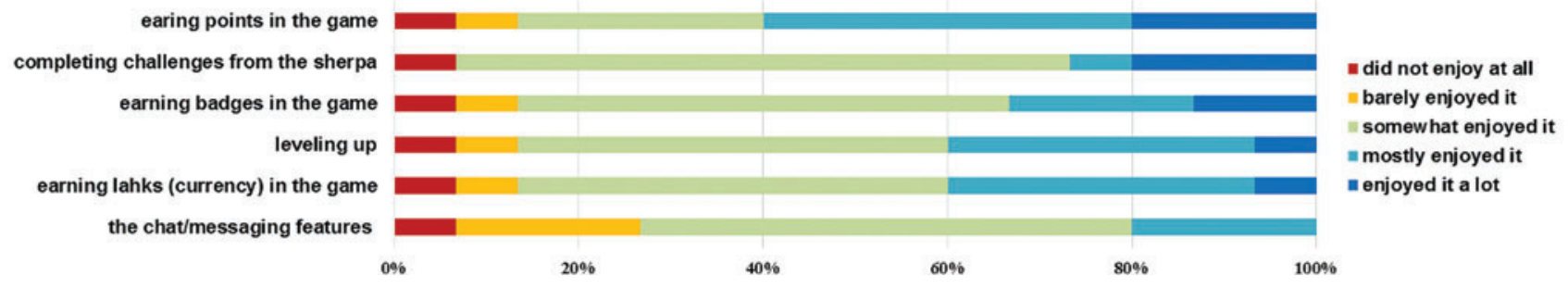

FIG. 4. Participant satisfaction with respect to ease of use of the app and enjoyment $(n=15)$. Color images are available online. 
Table 4. Mean and Standard Deviations FOR TRANSPORTATION NARRATIVE QUESTIONNAIRE ITEMS

\begin{tabular}{|c|c|c|}
\hline & Mean & $S$ \\
\hline $\begin{array}{l}\text { After finishing the narrative, I found it easy } \\
\text { to put it out of my mind (reverse scored) }\end{array}$ & 3.9 & 1 \\
\hline $\begin{array}{l}\text { While I was reading the narrative, I could } \\
\text { easily picture the events in it taking place. }\end{array}$ & 3.9 & \\
\hline $\begin{array}{l}\text { I found my mind wandering while reading } \\
\text { the narrative (reverse scored) }\end{array}$ & 3.6 & \\
\hline I wanted to learn how the narrative ended. & 3.6 & 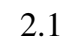 \\
\hline $\begin{array}{l}\text { I found myself thinking of ways the narrative } \\
\text { could have turned out differently. }\end{array}$ & 3.2 & \\
\hline $\begin{array}{l}\text { I was mentally involved in the narrative } \\
\text { while reading it. }\end{array}$ & 2.9 & 1 \\
\hline $\begin{array}{l}\text { I could picture myself in the scene of the } \\
\text { events described in the narrative. }\end{array}$ & 2.7 & 1 \\
\hline $\begin{array}{l}\text { While I was reading the narrative, activity } \\
\text { going on in the room around me was on } \\
\text { my mind (reverse scored) }\end{array}$ & 2.5 & 1 \\
\hline $\begin{array}{l}\text { The events in the narrative are relevant to my } \\
\text { everyday life. }\end{array}$ & 2.1 & 1 \\
\hline affected me emotionally. & 1.7 & 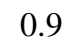 \\
\hline $\begin{array}{l}\text { The events in the narrative have changed my } \\
\text { life. }\end{array}$ & 1.7 & \\
\hline
\end{tabular}

Responses assessed on a 5-point Likert scale, ranging from Not At All (1) to Very Much (5).

had sharper declines in MVPA and increased their sedentary activity whereas those who used the app maintained their baseline status and neither increased nor decreased their MVPA or sedentary activity. Another goal of the intervention and app was to change dietary patterns, specifically to reduce intake of unhealthy foods and reduce consumption of sugary beverages. The stoplight diet was used to help participants identify those foods and beverages to avoid or eat in moderation and one of the tasks was to monitor intake of these foods and beverages. There were no changes in dietary patterns related to fruit, vegetable, or fat intake, but we did find a trend toward decreased intake of sugar from beverages among those using the app compared with those not using the app.

An unexpected finding, however, was a significant groupby-time interaction for percent of calories from sweet foods with an increasing trend observed among those using the app, those not using the app remaining unchanged from baseline. It may be that a future iteration of the diet-tracking feature of the app will need to focus on sugar intake overall, in addition to using the traffic light diet approach, which tends to focus more on fat intake. Overall, caution is warranted in interpreting these observations and trends in the data because it was not the intent to test these outcomes in this study. Rather, the goal was to build the app and intervention and evaluate feasibility and acceptability. The outcomes related to these metrics are supportive of future work that would use this approach and test behavioral outcomes in a larger randomized design.

Despite our initial successes with respect to feasibility and acceptability, we did experience some challenges. We encountered difficulties addressing technical bugs during the implementation stage, and there were additional costs and time required to develop the backend dashboard allowing for the research team to modify the game design features to see in real-time what was occurring in the game. Additionally, several participants had their own personal smartphones, and often forgot to interact with the app on the study devices. A future iteration of the app would be designed for different operating platforms and allow users to download the app on their personal phones. Also, given some of the feedback during the exit focus group, we would likely include parents, simplify the storyline, and enhance the player's ability to monitor their own individual-level progress.

This study has several limitations that should be considered when interpreting the results. First, the single-arm, nonrandomized design, while useful for testing feasibility of an intervention, has a number of biases that limit interpretation of the effectiveness. Second, we employed a number of post hoc analyses comparing users to nonusers to evaluate trends in the data, but the small sample size and the post hoc prevents us from concluding definitively that use of the app will result in beneficial gains in health behaviors. Finally, the sample lacked diversity with respect to race/ethnicity, and thus future iterations of this approach would benefit from attempts to reach a more diverse group of survivors.

In sum, we developed one of the first digitally mediated systems for delivering evidence-based health promotion recommendations using a health behavior coach and game mechanics. ${ }^{40}$ The app-based game was designed to promote healthy eating and PA among adolescent survivors of pediatric cancer. The preliminary evaluation showed acceptability and feasibility as a modality for the promotion of health behavior change among this young population of cancer survivors. Given the myriad of health comorbidities among adolescent survivors of pediatric cancer, there is a need to advance efforts that will address and support healthy lifestyle behaviors in this clinical population. ${ }^{41}$ Rather than focusing on increasing risk awareness and health education, "gamifying" the process of engaging in healthy lifestyle behaviors may be more appealing to this group of survivors. Furthermore, this approach could prove to be useful within other adolescent populations. Future studies are needed that can evaluate these methods in largerscale clinical trials.

\section{Disclaimer}

The contents are solely the responsibility of the authors and do not necessarily represent the official views of $\mathrm{NCI} \mid \mathrm{NIH}$. Furthermore, NCI does not endorse the purchase of any commercial products or services mentioned in the publication.

\section{Author Disclosure Statement}

No competing financial interests exist.

\section{Funding Information}

Research reported in this publication was supported by the National Cancer Institute (NCI) | National Institutes of Health (NIH) 1R21CA155965-01 and a NCI T32 award (2T32CA093423).

\section{References}

1. Zhang FF, Kelly MJ, Saltzman E, et al. Obesity in pediatric ALL survivors: A meta-analysis. Pediatrics 2014; 133:e704 e715. 
2. Zhang FF, Parsons SK. Obesity in childhood cancer survivors: Call for early weight management. Adv Nutr 2015; 6:611-619.

3. Elsbernd A, Hjerming M, Visler C, et al. Cocreated smartphone app to improve quality of life of adolescents and young adults with cancer (Kraeftvaerket): Protocol for a quantitative and qualitative evaluation. JMIR Res Protoc 2018; 7(5):e10098.

4. Hunger SP, Mullighan CG. Acute lymphoblastic leukemia in children. N Engl J Med 2015; 373:1541-1552.

5. Turcotte LM, Liu Q, Yasui Y, et al. Subsequent malignant neoplasms (SMNs) among non-irradiated survivors of childhood cancer treated with chemotherapy in the Childhood Cancer Survivor Study. In: American Society of Clinical Oncology; 2018.

6. Demark-Wahnefried W, Werner C, Clipp EC, et al. Survivors of childhood cancer and their guardians. Cancer 2005; 103:2171-2180.

7. Jenney ME, Faragher EB, Jones PH, Woodcock A. Lung function and exercise capacity in survivors of childhood leukaemia. Med Pediatr Oncol 1995; 24:222-230.

8. Matthys D, Verhaaren H, Benoit Y, et al. Gender difference in aerobic capacity in adolescents after cure from malignant disease in childhood. Acta Paediatr 1993; 82: 459-462.

9. Ness KK, Leisenring WM, Huang S, et al. Predictors of inactive lifestyle among adult survivors of childhood cancer: A report from the Childhood Cancer Survivor Study. Cancer 2009; 115:1984-1994.

10. Robien K, Ness KK, Klesges LM, et al. Poor adherence to dietary guidelines among adult survivors of childhood acute lymphoblastic leukemia. J Pediat Hematol Onc 2008; 30:815-822.

11. Rogers PC, Meacham LR, Oeffinger KC, et al. Obesity in pediatric oncology. Pediatr Blood Cancer 2005; 45:881891.

12. Oeffinger KC, Buchanan GR, Eshelman DA, et al. Cardiovascular risk factors in young adult survivors of childhood acute lymphoblastic leukemia. J Pediat Hematol Oncol 2001; 23:424-430.

13. Fuemmeler BF, Pendzich MK, Clark K, et al. Diet, physical activity, and body composition changes during the first year of treatment for childhood acute leukemia and lymphoma. J Pediat Hematol Oncol 2013; 35:437443.

14. Aziz NM, Oeffinger KC, Brooks S, Turoff AJ. Comprehensive long-term follow-up programs for pediatric cancer survivors. Cancer 2006; 107:841-848.

15. Nathan PC, Ford JS, Henderson TO, et al. Health behaviors, medical care, and interventions to promote healthy living in the Childhood Cancer Survivor Study cohort. J Clin Oncol 2009; 27:2363-2373.

16. Spagnolli A, Chittaro L, Gamberini L. Persuasive Technology. 9th International Conference, PERSUASIVE 2014, Padua, Italy, May 21-23, 2014. Proceedings: Springer, Cham; 2014.

17. Tripette J, Murakami H, Gando Y, et al. Home-based active video games to promote weight loss during the postpartum period. Med Sci Sport Exer 2014; 46:472-478.

18. Coughlin S, Jacobs M, Thind H, et al. On the need for research-tested smartphone applications for reducing exposures to known or suspected breast carcinogens in work and home environments. J Environ Health Sci 2015 ; 1(4)10.15436/2378-6841.15 e004.
19. Wesley K, Fizur P. A review of mobile applications to help adolescent and young adult cancer patients. Adolesc Health Med Ther 2015; 6:141-148.

20. Bernsten E, Babic A. Cherry: Mobile application for children with cancer. Stud Health Technol Inform 2013; 192: 1168.

21. Rodgers C, Krance R, Street R, Hockenberry M. Feasibility of a symptom management intervention for adolescents recovering from hematopoietic stem cell transplant. Cancer Nurs 2013; 36:394-399.

22. Przybylski AK, Ryan RM, Rigby CS. The motivating role of violence in video games. Pers Soc Psychol Bull 2009; 35:243-259.

23. Ryan RM, Rigby CS, Przybylski A. The motivational pull of video games: A self-determination theory approach. Motiv Emotion 2006; 30:347-363.

24. Johnson D, Deterding S, Kuhn K-A, et al. Gamification for health and wellbeing: A systematic review of the literature. Internet Interv 2016; 6:89-106.

25. Green MC, Brock TC. In the Mind's Eye: TransportationImagery Model of Narrative Persuasion. Mahwah, NJ: Lawrence Erlbaum Associates Publishers; 2002.

26. Green MC, Garst J, Brock TC. The Power of Fiction: Determinants and Boundaries. Mahwah, NJ: Lawrence Erlbaum Associates Publishers; 2004.

27. McGonigal J. Reality is Broken: Why Games Make Us Better and How They can Change the World. New York, NY: Penguin Press; 2011.

28. Burke LE, Conroy MB, Sereika SM, et al. The effect of electronic self-monitoring on weight loss and dietary intake: A randomized behavioral weight loss trial. Obesity 2011; 19:338-344.

29. Epstein LH. Development of evidence-based treatments for pediatric obesity In: Kazdin AE, Weisz JR, eds. Evidence-Based Psychotherapies for Children and Adolescents. New York: Guilford Publications, Inc.; 2003: 374-388.

30. Harvard School of Public Health. The Nutrition Source: Choosing Healthy Drinks. www.hsph.harvard.edu/nutrition source/healthy-drinks/ (accessed October 9, 2009).

31. Kuczmarski RJ, Ogden CL, Guo SS, et al. 2000 CDC growth charts for the United States: Methods and development. Vital and Health Statistics Series 11, 2002(246):1190.

32. Block G, Hartman AM, Dresser CM, et al. A data-based approach to diet questionnaire design and testing. Am J Epidemiol 1986; 124:453-469.

33. Cullen KW, Watson K, Zakeri I. Relative reliability and validity of the Block Kids Questionnaire among youth aged 10 to 17 years. J Am Diet Assoc 2008; 108:862866.

34. Marshall TA, Eichenberger Gilmore JM, Broffitt B, et al. Relative validity of the Iowa Fluoride Study targeted nutrient semi-quantitative questionnaire and the block kids' food questionnaire for estimating beverage, calcium, and vitamin D intakes by children. J Am Diet Assoc 2008; 108: 465-472.

35. NutritionQuest. NutritionQuest. 2018; http://nutritionquest .com/ (accessed December 20, 2018).

36. Freedson P, Pober D, Janz KF. Calibration of accelerometer output for children. Med Sci Sports Exerc 2005; 37(11 Suppl): S523-S530.

37. Norman GJ, Sallis JF, Gaskins R. Comparability and reliability of paper- and computer-based measures of 
psychosocial constructs for adolescent physical activity and sedentary behaviors. Res Q Exerc Sport 2005; 76: 315-323.

38. Hagler AS, Norman GJ, Radick LR, et al. Comparability and reliability of paper- and computer-based measures of psychosocial constructs for adolescent fruit and vegetable and dietary fat intake. J Am Diet Assoc 2005; 105:1758-1764.

39. Green MC, Brock TC. The role of transportation in the persuasiveness of public narratives. J Pers Soc Psychol 2000; 79:701-721.

40. Fuemmeler B. Inventor. Methods, systems, and computer readable media for promoting behavioral intervention via evidence-based recommendations and game mechanics US patent US9483957 B1, Nov 1. 2016.
41. Daniel CL, Emmons KM, Fasciano K, et al. Needs and lifestyle challenges of adolescents and young adults with cancer: Summary of an Institute of Medicine and Livestrong Foundation Workshop. Clin J Oncol Nurs 2015; 19: 675-681.

Address correspondence to: Bernard F. Fuemmeler, PhD, MPH Department of Health Behavior and Policy Virginia Commonwealth University PO Box 980149, 830 E Main Street Richmond, VA 23219

E-mail: bernard.fuemmeler@vcuhealth.org 